\title{
External targeted navigation of ultra-small iron- oxide (U/SPIO) nanoparticles by an external permanent magnet - proof-of-principle as a prerequisite for magnetic drug delivery using $\mathrm{U} /$ SPIO
}

Michael Bietenbeck ${ }^{1 *}$, Verena Hoerr², Harald Kugel², Cornelius Faber ${ }^{2}$, Ali Yilmaz ${ }^{1}$

From 18th Annual SCMR Scientific Sessions

Nice, France. 4-7 February 2015

\section{Background}

Recently, we could demonstrate in humans that (ultrasmall) superparamagnetic iron-oxide (U/SPIO)-based contrast agents enable a detailed characterization of myocardial infarct pathology. Considering the multifunctionality of U/SPIO-based nanoparticles (magnetic targeting as well as diagnostic imaging properties) and their superior safety profile compared to gadoliniumbased compounds, we performed ex vivo analyses and evaluated the magnetic navigating/targeting properties of U/SPIO.

\section{Methods}

Using a self-constructed closed circuit with a manually tunable pump and an external permanent magnet, the targeting properties of ferucarbotran (U/SPIO) were evaluated. Using a concentration of ferucarbotran similar to the allowed concentration for human use, our self-constructed system allowed us to modify the following parameters: a) the distance between our circuit and the permanent magnet, $b$ ) the velocity rate of circulation in our closed circuit and c) the duration of permanent magnet exposure. Drawing off of fluid from our circuit at the location of the permanent magnet allowed us to measure the concentration/accumulation of ferucarbotran using a 9.4-T magnetic resonance scanner and $\mathrm{T} 2{ }^{*}$ weighted sequences.

\section{Results}

Prior to starting the pump of our closed circuit and to introducing the magnet, the measured $\mathrm{T} 2 *$ value of our ferucarbotran-solution was $35.7 \mathrm{~ms}$ (using an iron concentration of $5 \mu \mathrm{g}$ iron $/ \mathrm{ml}$ water in our circuit). Using a velocity rate of $20 \mathrm{~cm} / \mathrm{sec}$, a magnet exposure duration of only $5 \mathrm{~min}$ and a magnet distance of 0 resulted in a $\mathrm{T} 2 *$ value of $15.3 \mathrm{~ms}$ - indicating successful accumulation of iron particles. Increasing the distance of the magnet to $10 \mathrm{~mm}$ (while keeping other variables constant) lead to an increase in $\mathrm{T} 2 *$ to $28.2 \mathrm{~ms}$ - indicating a reduced accumulation of iron particles. Repeated measurements with modified parameters showed a) a (relative) increase in $\mathrm{T}^{*}$ when the distance of the magnet was increased, b) no relevant change in $\mathrm{T} 2 *$ when the velocity rate of circulation was changed between $5-35 \mathrm{~cm} / \mathrm{sec}$ and c) a (relative) decrease in $\mathrm{T} 2 *$ when the magnet exposure duration was increased.

\section{Conclusions}

External targeted navigation of U/SPIO (approved for human use) by an external permanent magnet is technically possible. U/SPIO may play an important future role in magnetic drug delivery and simultaneous diagnostic imaging and therapy surveillance.

\section{Funding}

None. 


\section{Authors' details}

'Department of Cardiology and Angiology, University Hospital Münster,

Münster, Germany. ${ }^{2}$ Translational Research Imaging Center, University

Hospital Münster, Münster, Germany.

Published: 3 February 2015

doi:10.1186/1532-429X-17-S1-P72

Cite this article as: Bietenbeck et al:: External targeted navigation of ultrasmall iron-oxide (U/SPIO) nanoparticles by an external permanent magnet - proof-of-principle as a prerequisite for magnetic drug delivery using U/

SPIO. Journal of Cardiovascular Magnetic Resonance 2015 17(Suppl 1):P72.

Submit your next manuscript to BioMed Central and take full advantage of:

- Convenient online submission

- Thorough peer review

- No space constraints or color figure charges

- Immediate publication on acceptance

- Inclusion in PubMed, CAS, Scopus and Google Scholar

- Research which is freely available for redistribution

Submit your manuscript at www.biomedcentral.com/submit
C Biomed Central 